\title{
$\pi$-Stacking Stopper-Macrocycle Stabilized Dynamically Interlocked [2]Rotaxanes
}

\author{
Sing-Ming Chan ${ }^{1}$, Fung-Kit Tang ${ }^{1}$, Ching-Yau Lam ${ }^{1}$, Chak-Shing Kwan ${ }^{1}$, Sam C. K. Hau ${ }^{2, *}$ (1) \\ and Ken Cham-Fai Leung $1, * \mathbb{D}$ \\ 1 State Key Laboratory of Environmental and Biological Analysis, Department of Chemistry, The Hong Kong \\ Baptist University, Kowloon Tong, Kowloon, Hong Kong, China; 17482100@life.hkbu.edu.hk (S.-M.C.); \\ 18482503@life.hkbu.edu.hk (F.-K.T.); 16213769@life.hkbu.edu.hk (C.-Y.L.); \\ 14485761@life.hkbu.edu.hk (C.-S.K.) \\ 2 Department of Chemistry, The Chinese University of Hong Kong, Shatin, NT, Hong Kong, China \\ * Correspondence: sckhau@cuhk.edu.hk (S.C.K.H.); cfleung@hkbu.edu.hk (K.C.-F.L.)
}

Citation: Chan, S.-M.; Tang, F.-K.; Lam, C.-Y.; Kwan, C.-S.; Hau, S.C.K.; Leung, K.C.-F. $\pi$-Stacking Stopper-Macrocycle Stabilized Dynamically Interlocked [2]Rotaxanes. Molecules 2021, 26, 4704 https: / / doi.org/10.3390/ molecules26154704

Academic Editor: Hiroyuki Takemura

Received: 16 July 2021

Accepted: 1 August 2021

Published: 3 August 2021

Publisher's Note: MDPI stays neutral with regard to jurisdictional claims in published maps and institutional affiliations.

Copyright: (c) 2021 by the authors. Licensee MDPI, Basel, Switzerland. This article is an open access article distributed under the terms and conditions of the Creative Commons Attribution (CC BY) license (https:// creativecommons.org/licenses/by/ $4.0 /)$.

\begin{abstract}
The synthesis of mechanically interlocked molecules is valuable due to their unique topologies. With $\pi$-stacking intercomponent interaction, e.g., phenanthroline and anthracene, novel [2]rotaxanes have been synthesized by dynamic imine clipping reaction. Their X-ray crystal structures indicate the $\pi$-stackings between the anthracene moiety (stopper) on the thread and the (hetero)aromatic rings at the macrocycle of the rotaxanes. Moreover, the length of glycol chains affects the extra $\pi$-stacking intercomponent interactions between the phenyl groups and the dimethoxy phenyl groups on the thread. Dynamic combinatorial library has shown at best $84 \%$ distribution of anthracene-threaded phenanthroline-based rotaxane, coinciding with the crystallography in that the additional $\pi$-stacking intercomponent interactions could increase the thermodynamic stability and selectivity of the rotaxanes.
\end{abstract}

Keywords: dynamic combinatorial library; imine macrocycle; intercomponent interaction; $\pi$-stacking; rotaxane synthesis

\section{Introduction}

The synthesis of mechanically interlocked molecules, such as [n]rotaxanes and [n]catenanes [1-4], has drawn interest due to their unique topologies. They have been applied in the designs of molecular machinery [5-8] and molecular sensing [9-14]. For the $[n]$ rotaxanes, templated-direct syntheses using secondary dialkylammonium $\left(\mathrm{R}_{2} \mathrm{NH}_{2}{ }^{+}\right)$ ions are involved in threading followed by stoppering [15], slippage [16-19] and clipping approaches [20,21] Various macrocycles, such as dibenzo[24]crown-8 (DB24C8) and benzo[21]crown-7 (B21C7), can be threaded through by the dialkylammonium $\left(\mathrm{R}_{2} \mathrm{NH}_{2}{ }^{+}\right)$ ions with sufficiently high binding constant [22-24].

In 2001, Stoddart and co-workers developed the dynamic clipping on $\mathrm{R}_{2} \mathrm{NH}_{2}{ }^{+}$ions for [2]rotaxane synthesis [25]. As being part of the dynamic covalent chemistry (DCC) [21,26,27], the dynamic clipping approach allows self-error checking and self-sorting to favor the most thermodynamically stable rotaxane as the major product based on equilibrium reactions. Besides [2]rotaxanes, efficient methods for constructing dendritic [ $n$ ]rotaxanes [28-32] homocircuit [ $n$ ]rotaxanes [33-38] and heterocircuit [ $n$ ]rotaxanes [39-45] have recently been investigated.

Meanwhile, the synthetic complexity could raise if the number of recognition sites increases or the thread became unsymmetrical. Indeed, the co-conformational [2]rotaxane isomers should have good stability to avoid isomerization by molecular shuttling. Therefore, developing a selective synthesis of dynamic [2]rotaxane with only one of $\mathrm{R}_{2} \mathrm{NH}_{2}{ }^{+}$ ions recognition site occupied by macrocycle is highly critical.

Herein, we report new phenanthroline-based rotaxanes by employing 1,10-phenanthroline2,9-dicarbaldehyde (dialdehyde 1) to form dynamic imine macrocycle. In the presence 
of the anthracene moiety, additional $\pi$-stacking between the phenanthroline unit and anthracene unit is observed in the solid-state structures of [2]rotaxanes, indicating further stabilization of the interlocked structure. The $\pi$-stacking at the stopper offers a higher specificity on rotaxane synthesis, making anthracene threaded phenanthroline-based rotaxanes as the major products in dynamic combinatorial library competing with other threads.

\section{Results and Discussion}

The 2,6-pyridine dicarboxaldehyde (dialdehyde 2) and tetraethylene glycol bis(2aminophenyl)ether (diamine 3 ) were used for the synthesis of rotaxanes $[14,25,36,46]$ by the clipping approach. For instance, $\mathbf{1 0}-\mathrm{H} \cdot \mathrm{PF}_{6}$ and its stability in the presence of water and acid were reported [47]. As the stopper of rotaxanes, the anthracene unit was adopted due to its fluorescence property and bulkiness. Although the crystal structures of [3]rotaxane [36,42] nickel(II)-salen [2]rotaxane [48,49] and triimine [2]rotaxanes [50,51] had been previously reported, single crystals of pure organic diimine [2]rotaxane were not discovered yet.

To verify the intercomponent stabilization [52-57], rotaxanes with stronger $\pi$-stacking interaction were synthesized. Dialdehyde 1 was selected due to its conjugated aromatic structure. By mixing equimolar amounts of thread $5-\mathrm{H} \cdot \mathrm{PF}_{6}$, dialdehyde $\mathbf{1}$ and diamine 3 in $\mathrm{MeCN}$ at room temperature (Scheme 1), the crude ${ }^{1} \mathrm{H}$ NMR spectrum (Figure $1 \mathrm{~b}$ ) of the reaction mixtures reveals total consumption of the starting materials to the respective [2]rotaxane, 8-H. $\mathrm{PF}_{6}$. The disappearance of the aldehyde proton $-\mathrm{CHO}$ resonance at ca. $10.2 \mathrm{ppm}$ supports the complete consumption of the dialdehyde compound in the reaction. Meanwhile, the characteristic signal for the benzylic methylene group $-\mathrm{CH}_{2}$ protons adjacent to the $\mathrm{R}_{2} \mathrm{NH}_{2}{ }^{+}$center was shifted and split from $\delta=5.2$ and $4.4 \mathrm{ppm}$ in thread $5-\mathrm{H} \cdot \mathrm{PF}_{6}$ to $\delta=5.75-5.64$ and $4.72-4.60 \mathrm{ppm}$ in rotaxane $8-\mathrm{H} \cdot \mathrm{PF}_{6}$, indicating its encirclement by the crown ether rings (Table S1). Hence, the macrocycle formed in the reaction contains two more carbon atoms and one more nitrogen atom compared to that of dialdehyde 2, making 8- $\mathrm{H} \cdot \mathrm{PF}_{6}$ a [27]crown-9 rotaxane. Moreover, by changing the diamine from 3 to 4 , [24] crown-8 rotaxane $9-\mathrm{H} \cdot \mathrm{PF}_{6}$ was obtained in high yield. For dialdehyde 2 , only [24]crown-8 rotaxane $10-\mathrm{H} \cdot \mathrm{PF}_{6}$ and $14-\mathrm{H} \cdot \mathrm{PF}_{6}$ were obtained possibly due to the weaker $\pi-\pi$ stacking stabilization.

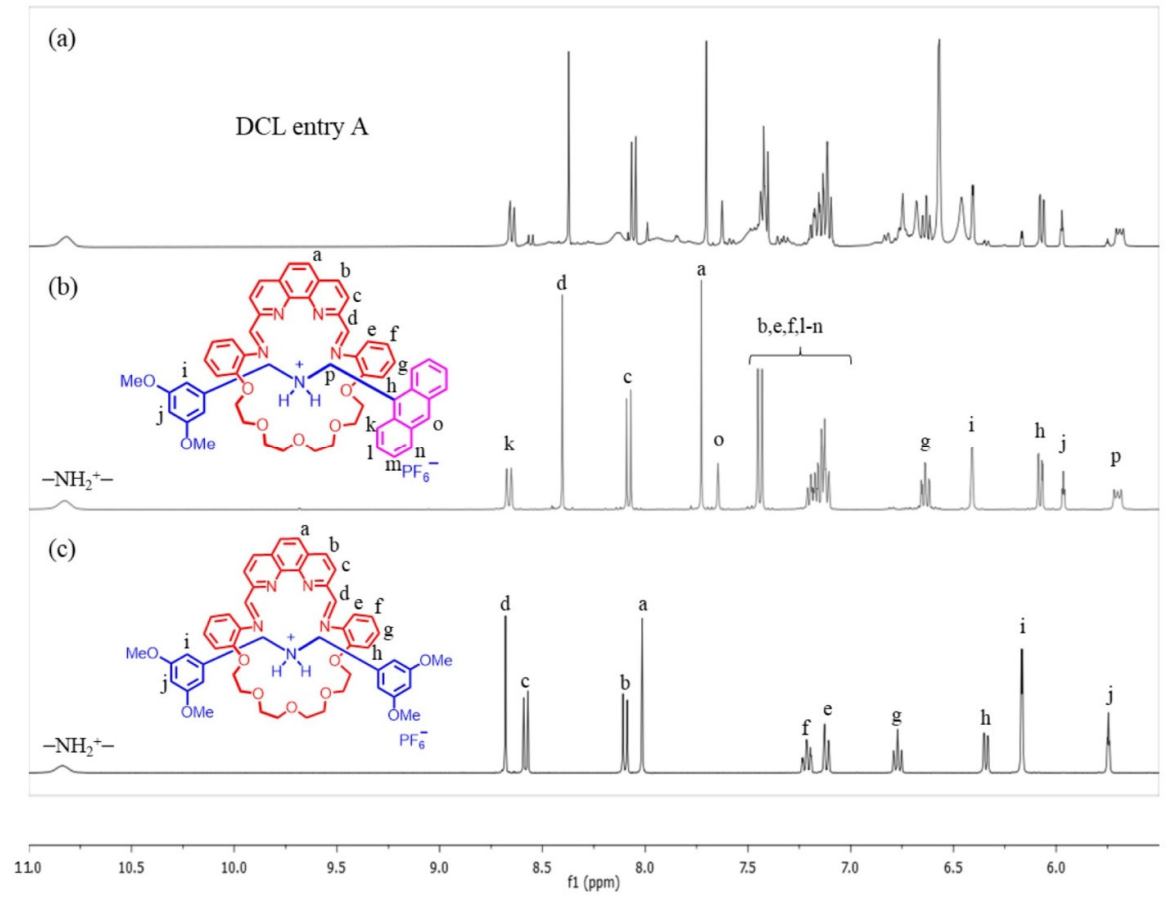

Figure 1. Partial, stacked ${ }^{1} \mathrm{H}$ NMR spectra $\left(\mathrm{CD}_{3} \mathrm{CN}, 400 \mathrm{MHz}, 298 \mathrm{~K}\right)$ of (a) dynamic combinatorial library (DCL) entry A; (b) 8-H.PF 6 ; and (c) $12-\mathrm{H} \cdot \mathrm{PF}_{6}$. 
(a)

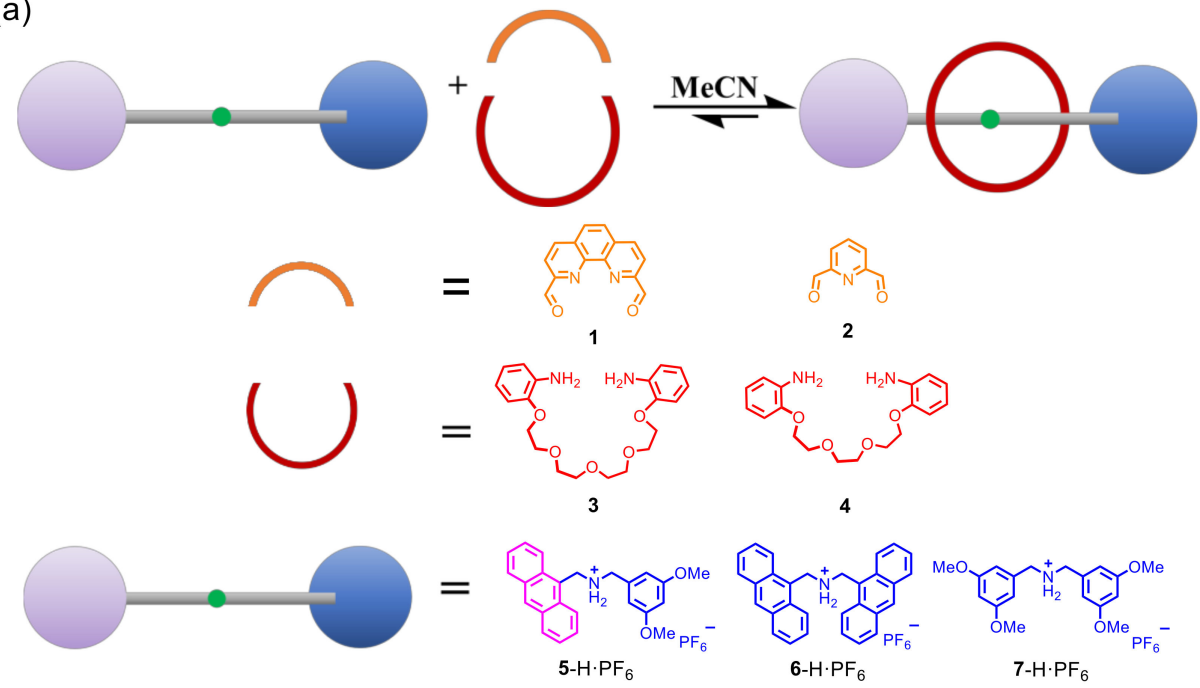

(b)

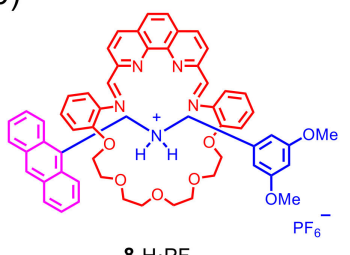

8-H.PF 6

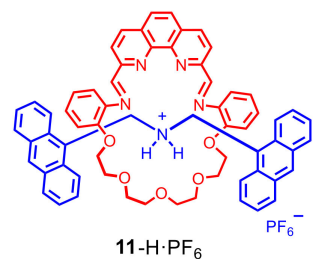

$11-\mathrm{H} \cdot \mathrm{PF}_{6}$

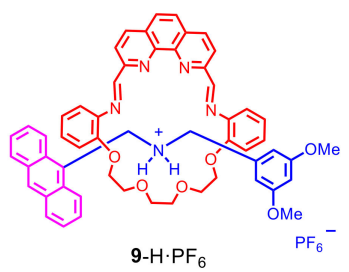

9-H.PF
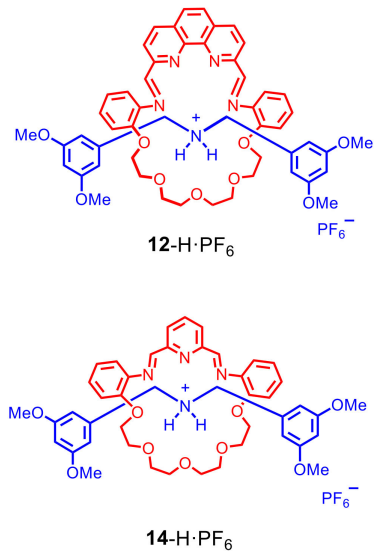
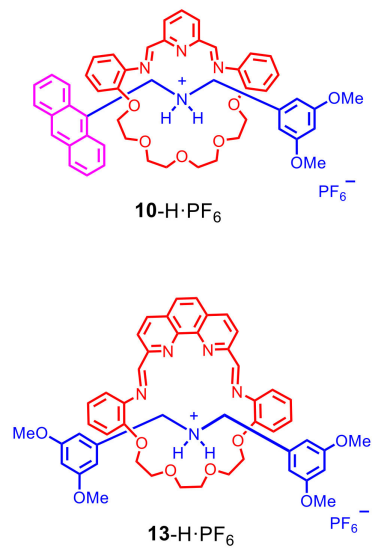

$13-\mathrm{H} \cdot \mathrm{PF}_{6}$ 
between the two phenyl rings for $9-\mathrm{H} \cdot \mathrm{PF}_{6}$ is $3.882 \AA$. The solid-state structures suggest that the $\pi$-stacking between the anthracene and the phenanthroline possesses a stronger interaction which can further stabilize the [2]rotaxanes. Moreover, the phenanthroline unit is taking a more important role than the ethylene glycol units on formation of the [2]rotaxanes.

w.

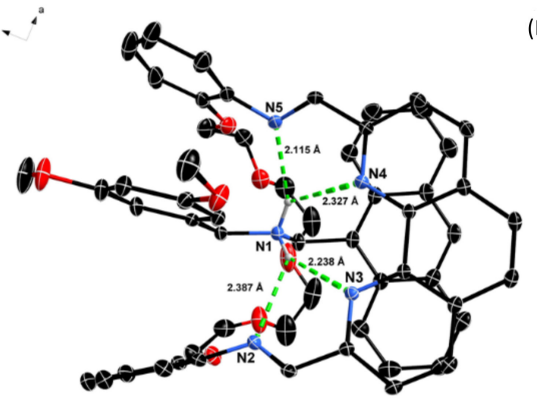

(C)

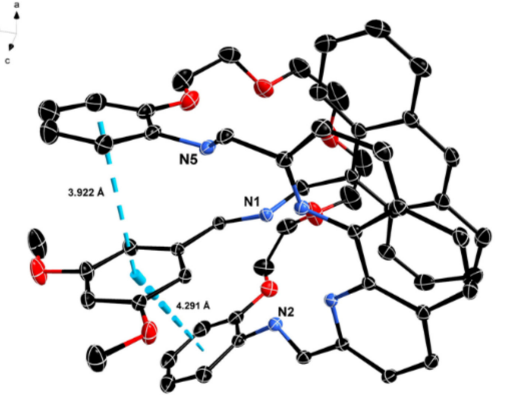

(E)

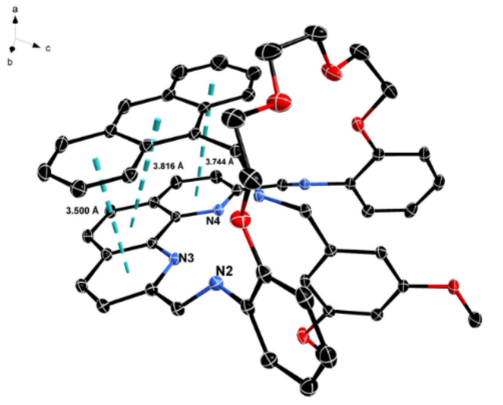

(B) $\because$

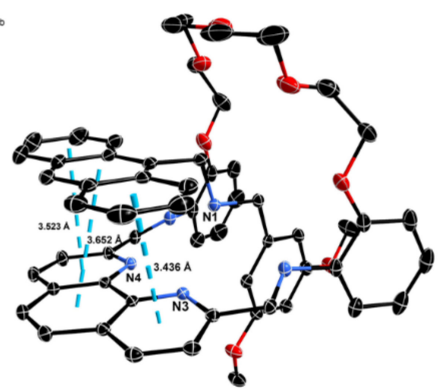

(D) ${ }^{\circ}$

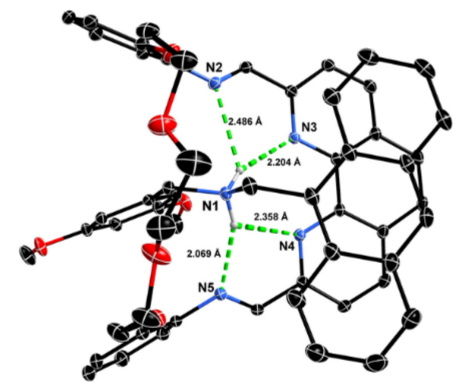

(F) $\because$

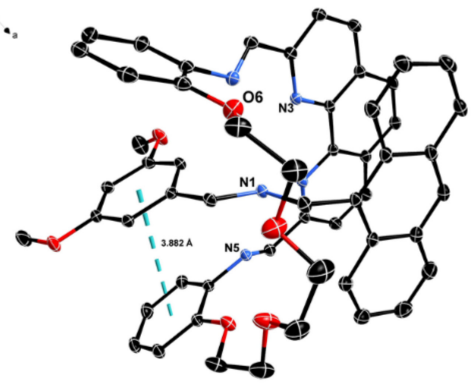

(G)

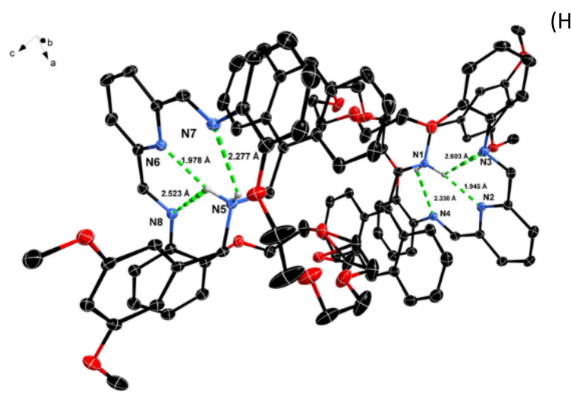

(H)
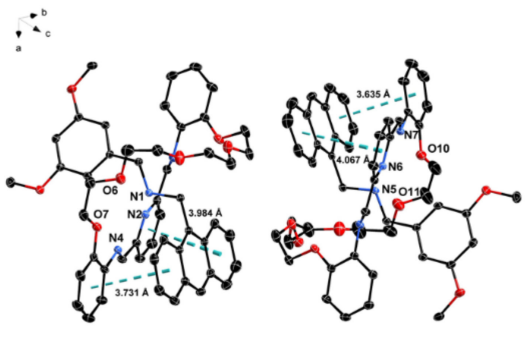

Figure 2. Perspective view of (A) solid-state structures of dynamic rotaxane $8-\mathrm{H} \cdot \mathrm{PF}_{6}(\mathrm{CCDC}$ code: 1993136); (B) the offset face-to-face $\pi-\pi$ stacking intercomponent interaction between the anthracene and phenanthroline in $8-\mathrm{H} \cdot \mathrm{PF}_{6}$; (C) the offset face-to-face $\pi-\pi$ stacking intercomponent interaction between the phenyl moieties in $8-\mathrm{H} \cdot \mathrm{PF}_{6}$; (D) solid-state structures of dynamic rotaxane $9-\mathrm{H} \cdot \mathrm{PF}_{6}$ (CCDC code: 1993139); (E) the offset face-to-face $\pi-\pi$ stacking intercomponent interaction between the anthracene and phenanthroline in $9-\mathrm{H} \cdot \mathrm{PF}_{6} ;(\mathbf{F})$ the offset face-to-face $\pi-\pi$ stacking intercomponent interaction between the phenyl moieties in $9-\mathrm{H} \cdot \mathrm{PF}_{6} ;(\mathbf{G})$ solid-state structures of dynamic rotaxane 10-H. $\mathrm{PF}_{6}(\mathrm{CCDC}$ code: 1993140$) ;(\mathbf{H})$ the offset face-to-face $\pi-\pi$ stacking intercomponent interaction between the anthracene and pyridine in $\mathbf{1 0}-\mathrm{H} \cdot \mathrm{PF}_{6}$. All hydrogen atoms and $\mathrm{PF}_{6}{ }^{-}$anions are omitted for clarity. 
By slow evaporation of the MeCN solution of $10-\mathrm{H} \cdot \mathrm{PF}_{6}$, single crystal was obtained and analyzed by $\mathrm{X}$-ray crystallography. In addition to the $\left[\mathrm{N}^{+}-\mathrm{H} \cdots \mathrm{N}\right]$ interaction, the solid-state structure of $\mathbf{1 0}-\mathrm{H} \cdot \mathrm{PF}_{6}$ (Figure $2 \mathrm{G}, \mathrm{H}$ ) shows aromatic $\pi-\pi$ stacking interactions between the anthracene and phenyl unit with center to center $\pi-\pi$ stacking interaction distance: $3.636 \AA$. With the $\pi$-stacking intercomponent interactions between the stopper and the macrocycle, the anthracene thread can be stabilized the rotaxane formation and allows the isolation of rotaxanes.

In order to test the compatibility of the formation of dynamic rotaxanes, other stoppers for clipping were used. In particular, threads $6-\mathrm{H} \cdot \mathrm{PF}_{6}$ and $7-\mathrm{H} \cdot \mathrm{PF}_{6}$ were used to investigate the effect of the $\pi$-stacking interactions, while clipping with thread $7-\mathrm{H} \cdot \mathrm{PF}_{6}$ gave symmetrical rotaxanes $12-\mathrm{H} \cdot \mathrm{PF}_{6}$ and $13-\mathrm{H} \cdot \mathrm{PF}_{6}$ in high yields. ${ }^{1} \mathrm{H}$ NMR signals of the phenanthroline unit in $\mathbf{1 2}-\mathrm{H} \cdot \mathrm{PF}_{6}$ and $\mathbf{1 3}-\mathrm{H} \cdot \mathrm{PF}_{6}$ have a significant difference in comparison to the signals in 8- $\mathrm{H} \cdot \mathrm{PF}_{6}$ and 9-H.PF 6 (Figure 1 and Figure S17, Table S1). For 8-H.PF, $\mathrm{H}_{\mathrm{a}}, \mathrm{H}_{\mathrm{b}}, \mathrm{H}_{\mathrm{c}}$ and $\mathrm{H}_{\mathrm{d}}$ were upfield-shifted from $\delta=8.01$ to $7.73 \mathrm{ppm}, \delta=8.10$ to $7.44 \mathrm{ppm}$, $\delta=8.58$ to $8.08 \mathrm{ppm}$ and $\delta=8.68$ to $8.40 \mathrm{ppm}$, respectively, compared to $12-\mathrm{H} \cdot \mathrm{PF}_{6}$. The upfield movement of phenanthroline aromatic proton signals of $8-\mathrm{H} \cdot \mathrm{PF}_{6}$ and $9-\mathrm{H} \cdot \mathrm{PF}_{6}$ can be due to the electron sharing from the electron-rich anthracene moiety. Moreover, phenanthroline aromatic proton was located in anisotropic-induced magnetic field of the anthracene moiety, so it is upfield shifted because of shielding effect. Both support the existence of the $\pi$-stacking interactions. For thread $6-\mathrm{H} \cdot \mathrm{PF}_{6}$, only rotaxane $11-\mathrm{H} \cdot \mathrm{PF}_{6}$ was obtained in low yield; changing the components to dialdehyde 2 or diamine $\mathbf{4}$ did not show a reasonable structure of rotaxane. This might be due to the strong intramolecular $\pi$-stacking between the two anthracene stoppers, so thread $6-\mathrm{H} \cdot \mathrm{PF}_{6}$ was folded and not reactive to form dynamic rotaxane. As a result, dialdehyde 1 allows more comprehensive combination to form dynamic rotaxane compared to dialdehyde $\mathbf{2}$, showing the potential of using phenanthroline for dynamic rotaxane synthesis.

After the successful synthesis of five new phenanthroline-based rotaxanes, dynamic combinatorial library (DCL) experiments were conducted to study the effect of $\pi$-stacking stabilization (Scheme 2). Threads $5-\mathrm{H} \cdot \mathrm{PF}_{6}$ and $7-\mathrm{H} \cdot \mathrm{PF}_{6}$ in 1:1 ratio were mixed with different dialdehydes and diamines in the reaction. As expected, there should be a competition on forming either anthracene-based or symmetrical rotaxane. The dominant product in each experimental entry should be more thermodynamically stable. Moreover, the temperature was set to $50{ }^{\circ} \mathrm{C}$ to maximize the thermodynamic selectivity of rotaxanes. After reacting for $18 \mathrm{~h}$, ratios of rotaxanes were determined by integrating the proton signals in the ${ }^{1} \mathrm{H}$ NMR spectra (Figure 1, Figures S17 and S18). As a result, ${ }^{1} \mathrm{H}$ NMR spectrum of dynamic combinatorial library experiment indicates that the thread $5-\mathrm{H} \cdot \mathrm{PF}_{6}$ was more favorable than $7-\mathrm{H} \cdot \mathrm{PF}_{6}$ to undergo rotaxane clipping with dialdehyde $1.8-\mathrm{H} \cdot \mathrm{PF}_{6}$ and 9-H. $\mathrm{PF}_{6}$ were preferentially formed as the dominant products, which have an $84: 16$ and 73:27 NMR yield ratios compared to the $12-\mathrm{H} \cdot \mathrm{PF}_{6}$ and $13-\mathrm{H} \cdot \mathrm{PF}_{6}$, respectively (Table 1 ). Moreover, the better selectivity in Entry A compared to Entry B may be due to the enhanced effect of the $\pi$-stacking interaction between the dimethyoxyphenyl moiety on stopper and the phenyl moiety on the macrocycle. While there was no preference for the synthesis of 10-H. $\mathrm{PF}_{6}$ and 14-H.PF 6 , 50:50 NMR yield ratio was obtained in entry $\mathrm{C}$ using the pyridine dialdehyde 2 . The reason is that the weak $\pi$-stacking interaction did not affect the stability of rotaxanes significantly, which further gives evidence of the phenanthroline unit in providing additional $\pi$-stacking interaction between the thread's stopper and the macrocycle. 


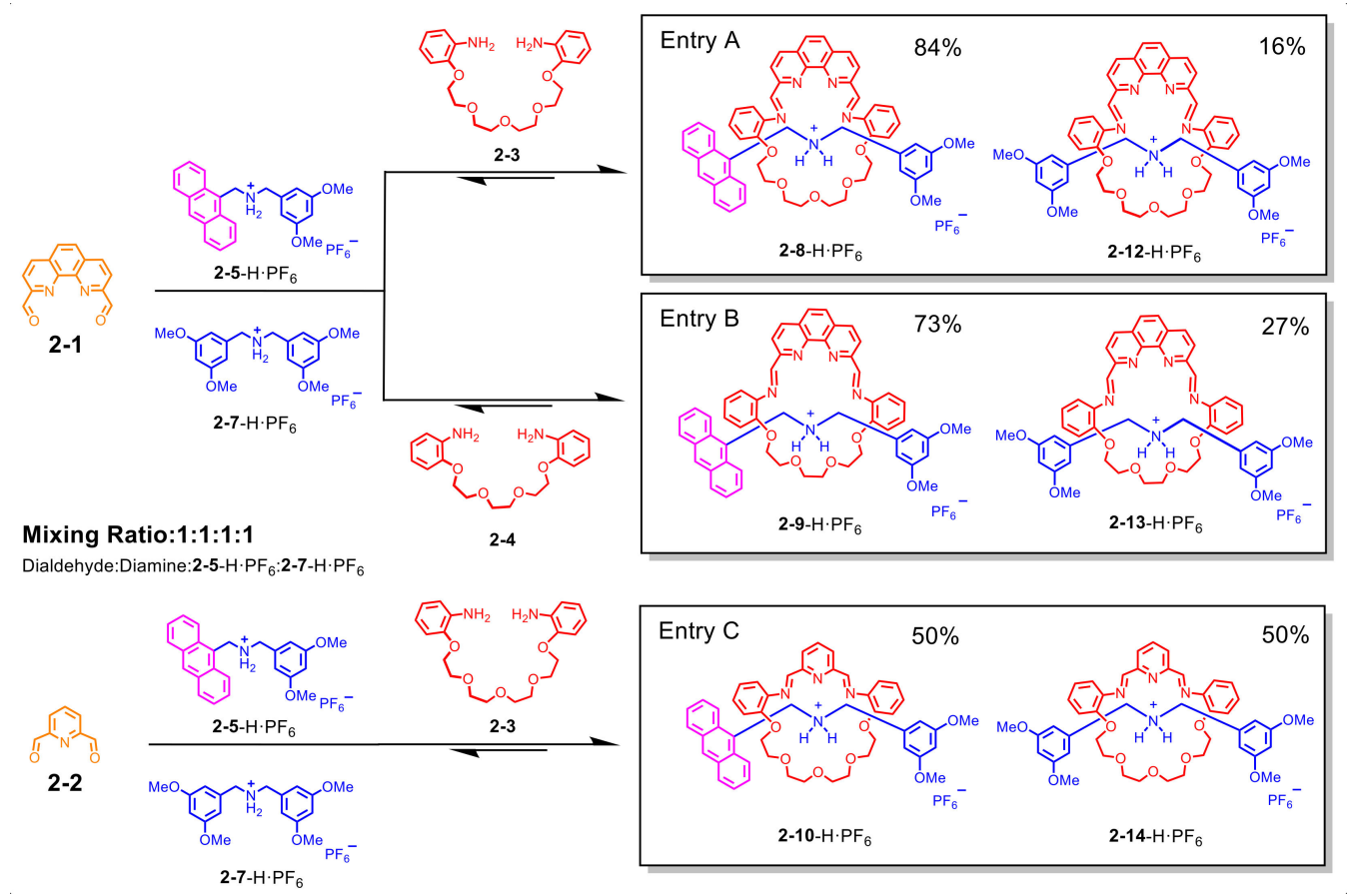

Scheme 2. Outcome of DCL entries A-C, by clipping of the dialdehydes $\mathbf{1}$ or $\mathbf{2}$ and diamine $\mathbf{3}$ or $\mathbf{4}$ with threads $5-\mathrm{H} \cdot \mathrm{PF}_{6}$ and $7-\mathrm{H} \cdot \mathrm{PF}_{6}$ to form the [2]rotaxanes.

Table 1. Dynamic combinatorial libraries (DCL) of rotaxane synthesis ${ }^{\mathrm{a}}$.

\begin{tabular}{|c|c|c|c|c|c|}
\hline DCL Entry & Thread & Diamine & Dialdehyde & Products & Yields $^{b}$ (Ratio) \\
\hline A & $5-\mathrm{H} \cdot \mathrm{PF}_{6}+7-\mathrm{H} \cdot \mathrm{PF}_{6}$ & 3 & 1 & $8-\mathrm{H} \cdot \mathrm{PF}_{6}+12-\mathrm{H} \cdot \mathrm{PF}_{6}$ & $84: 16$ \\
\hline $\mathrm{B}$ & $5-\mathrm{H} \cdot \mathrm{PF}_{6}+7-\mathrm{H} \cdot \mathrm{PF}_{6}$ & 4 & 1 & $9-\mathrm{H} \cdot \mathrm{PF}_{6}+13-\mathrm{H} \cdot \mathrm{PF}_{6}$ & $73: 27$ \\
\hline $\mathrm{C}$ & $5-\mathrm{H} \cdot \mathrm{PF}_{6}+7-\mathrm{H} \cdot \mathrm{PF}_{6}$ & 3 & 2 & $10-\mathrm{H} \cdot \mathrm{PF}_{6}+14-\mathrm{H} \cdot \mathrm{PF}_{6}$ & $50: 50$ \\
\hline
\end{tabular}

a Reagents and conditions: $0.1 \mathrm{mmol}$ of each thread, diamine, dialdehyde, $15 \mathrm{~mL}$ of MeCN, $0.1 \mathrm{~g}$ of $3 \AA$ molecular sieve, $50{ }^{\circ} \mathrm{C} .{ }^{\mathrm{b}}$ Ratios determined by ${ }^{1} \mathrm{H}$ NMR spectroscopic analysis of the reaction mixture after $18 \mathrm{~h}$.

\section{Materials and Methods}

Instrumentation and General experimental. Unless otherwise stated, all reagents and anhydrous solvents were purchased from commercial sources and used without further purification. Acetonitrile was distilled over calcium hydride. Dried acetonitrile was stored over $3 \AA$ molecular sieves. Flash column chromatography was performed using silica gel or aluminum oxide. Analytical TLC was performed on pre-coated silica gel plates ( $0.25 \mathrm{~mm}$ thick, 60F254, Merck, Darmstadt, Germany) and pre-coated ALUGRAM ${ }^{\circledR}$ (0.20 mm thick, F254, MN, Dueren, Germany). Spots were observed under UV light. ${ }^{1} \mathrm{H}$ and ${ }^{13} \mathrm{C}$ NMR spectra were recorded on a Bruker Advance-III spectrometer (at 400 and $101 \mathrm{MHz}$, respectively). Chemical shifts are reported in parts per million from low to high field and referenced to residual solvent $\left(\mathrm{CDCl}_{3}:{ }^{1} \mathrm{H}, 7.26 \mathrm{ppm} ;{ }^{13} \mathrm{C}, 77.16 \mathrm{ppm} . \mathrm{CD}_{3} \mathrm{CN}\right.$ : $\left.{ }^{1} \mathrm{H}, 1.94 \mathrm{ppm} ;{ }^{13} \mathrm{C}, 1.32 \mathrm{ppm}\right)$. NMR data were processed using MestReNova software (Mestrelab). Coupling constants are reported in Hertz. Standard abbreviations indicating multiplicity were used as follows: $\mathrm{m}=$ multiplet, quint $=$ quintet, $\mathrm{q}=$ quartet, $\mathrm{t}=$ triplet, $\mathrm{d}=$ doublet, $\mathrm{s}=$ singlet, $\mathrm{br}=$ broad. High-resolution mass spectra were recorded on a Bruker Autoflex mass spectrometer (MALDI-TOF) and a Thermo Fisher Scientific UPLC-Q exactive focus hybrid quadrupole-orbitrap mass spectrometer in positive ion mode (ESIMS). Selected crystals were used for intensity data collection on a Bruker AXS Kappa Apex II Duo diffractometer at $173 \mathrm{~K}$ using frames of oscillation range $0.3^{\circ}$, with $2^{\circ}<\theta<28^{\circ}$.

General procedure for synthesis of [2]rotaxanes. A solution of thread $(0.1 \mathrm{mmol})$ in $\mathrm{MeCN}(15 \mathrm{~mL})$ was added diamine $(0.1 \mathrm{mmol})$ and dialdehyde $(0.1 \mathrm{mmol})$. The yellow mixture was stirred for overnight at room temperature. The solvents were evaporated 
under reduced pressure. Product is isolated by recrystallization $\left(\mathrm{MeCN} / \mathrm{Et}_{2} \mathrm{O}\right)$ or column chromatography (neutral alumina, $\mathrm{CH}_{2} \mathrm{Cl}_{2} / n$-hexane).

General procedure for dynamic combinatorial library entries A-C. A solution of thread $5-\mathrm{H} \cdot \mathrm{PF}_{6}(0.1 \mathrm{mmol})$ and thread $7-\mathrm{H} \cdot \mathrm{PF}_{6}(0.1 \mathrm{mmol})$ in $\mathrm{MeCN}(15 \mathrm{~mL})$ was added a diamine $(0.1 \mathrm{mmol})$, dialdehyde $(0.1 \mathrm{mmol})$ and $0.1 \mathrm{~g}$ of $3 \AA$ molecular sieve. The yellow mixture was stirred for $18 \mathrm{~h}$ at $50^{\circ} \mathrm{C}$. The solvents were evaporated under reduced pressure. The ratio of rotaxanes in mixture was measured by ${ }^{1} \mathrm{H}$ NMR spectroscopy.

\section{Conclusions}

In conclusion, we had successfully synthesized new [2]rotaxanes by imine clipping reaction to form the macrocycle. $\pi$-Stacking intercomponent interactions between the macrocycle and the stopper of [2] rotaxanes $8-\mathrm{H} \cdot \mathrm{PF}_{6}, 9-\mathrm{H} \cdot \mathrm{PF}_{6}$ and $10-\mathrm{H} \cdot \mathrm{PF}_{6}$ were confirmed from their X-ray structural analysis. Intercomponent interactions were deduced and also corroborated in solution, besides solid state. Dynamic combinatorial library experiments of rotaxane formation resulted in phenanthroline-based rotaxanes with anthracene unit in threads as the major products, demonstrating the importance of $\pi$-stacking intercomponent interaction between the stopper and the macrocycle on the selective synthesis of the dynamic rotaxanes or related imine-based organic-inorganic hybrid materials [58].

Supplementary Materials: The following are available online: Experimental data of new compounds and X-ray crystallography data.

Author Contributions: Conceptualization, K.C.-F.L.; data curation, K.C.-F.L., S.C.K.H.; formal analysis, K.C.-F.L., S.C.K.H.; funding acquisition, K.C.-F.L.; methodology, S.-M.C., F.-K.T., C.-Y.L., C.-S.K., S.C.K.H., K.C.-F.L.; project administration, K.C.-F.L.; supervision, K.C.-F.L. All authors have read and agreed to the published version of the manuscript.

Funding: We acknowledge the financial support partially by The Hong Kong Baptist University (RC-KRPS-20-21/02).

Data Availability Statement: The data presented in this study are available on request from the corresponding authors.

Acknowledgments: We acknowledge Sir Fraser Stoddart (Department of Chemistry, Northwestern University) for helpful discussions. We thank Tao Wang (Department of Chemistry, Hong Kong Baptist University) for the ESI mass spectrometry analysis.

Conflicts of Interest: The authors declare no conflict of interest.

\section{References}

1. Stoddart, J.F.; Colquhoun, H.M. Big and Little Meccano. Tetrahedron 2008, 64, 8231-8263. [CrossRef]

2. Stoddart, J.F. The Chemistry of the Mechanical Bond. Chem. Soc. Rev. 2009, 38, 1802-1820. [CrossRef]

3. Beves, J.E.; Blight, B.A.; Campbell, C.J.; Leigh, D.A.; McBurney, R.T. Strategies and Tactics for the Metal-Directed Synthesis of Rotaxanes, Knots, Catenanes, and Higher Order Links. Angew. Chem. Int. Ed. 2011, 50, 9260-9327. [CrossRef]

4. Bruns, C.J.; Stoddart, J.F. The Nature of the Mechanical Bond; John Wiley \& Sons, Inc.: Hoboken, NJ, USA, 2016.

5. Yoon, I.; Benítez, D.; Zhao, Y.-L.; Miljanić, O.Š.; Kim, S.-Y.; Tkatchouk, E.; Leung, K.C.-F.; Khan, S.I.; Goddard, W.A., III; Stoddart, J.F. Functionally Rigid and Degenerate Molecular Shuttles. Chem. Eur. J. 2009, 15, 1115-1122. [CrossRef]

6. Schmidt-Schäffer, S.; Grubert, L.; Grummt, U.W.; Buck, K.; Abraham, W. A Photoswitchable Rotaxane with an Unfolded Molecular Thread. Eur. J. Org. Chem. 2006, 2006, 378-398. [CrossRef]

7. Leung, K.C.-F.; Nguyen, T.D.; Stoddart, J.F.; Zink, J.I. Supramolecular Nanovalves Controlled by Proton Abstraction and Competitive Binding. Chem. Mater. 2006, 18, 5919-5928. [CrossRef]

8. Nguyen, T.D.; Liu, Y.; Saha, S.; Leung, K.C.-F.; Stoddart, J.F.; Zink, J.I. Design and Optimization of Molecular Nanovalves Based on Redox-Switchable Bistable Rotaxanes. J. Am. Chem. Soc. 2007, 129, 626-634. [CrossRef] [PubMed]

9. Hiratani, K.; Kaneyama, M.; Nagawa, Y.; Koyama, E.; Kanesato, M. Synthesis of [1]Rotaxane via Covalent Bond Formation and Its Unique Fluorescent Response by Energy Transfer in the Presence of Lithium Ion. J. Am. Chem. Soc. 2004, 126, 13568-13569. [CrossRef] [PubMed]

10. Zhou, W.; Li, J.; He, X.; Li, C.; Lv, J.; Li, Y.; Wang, S.; Liu, H.; Zhu, D. A Molecular Shuttle for Driving a Multilevel Fluorescence Switch. Chem. Eur. J. 2008, 14, 754-763. [CrossRef] [PubMed]

11. Hancock, L.M.; Gilday, L.C.; Carvalho, S.; Costa, P.J.; Félix, V.; Serpell, C.J.; Kilah, N.L.; Beer, P.D. Rotaxanes Capable of Recognising Chloride in Aqueous Media. Chem. Eur. J. 2010, 16, 13082-13094. [CrossRef] 
12. Arumugaperumal, R.; Srinivasadesikan, V.; Ramakrishnam Raju, M.V.; Lin, M.-C.; Shukla, T.; Singh, R.; Lin, H.-C. Acid/Base and $\mathrm{H}_{2} \mathrm{PO}_{4}$ - Controllable High-Contrast Optical Molecular Switches with a Novel BODIPY Functionalized [2]Rotaxane. ACS Appl. Mater. Interfaces 2015, 7, 26491-26503. [CrossRef]

13. Denis, M.; Pancholi, J.; Jobe, K.; Watkinson, M.; Goldup, S.M. Chelating Rotaxane Ligands as Fluorescent Sensors for Metal Ions. Angew. Chem. Int. Ed. 2018, 57, 5310-5314. [CrossRef]

14. Chan, S.-M.; Tang, F.-K.; Kwan, C.-S.; Lam, C.-Y.; Hau, S.C.K.; Leung, K.C.-F. Water-Compatible Fluorescent [2]Rotaxanes for $\mathrm{Au}^{3+}$ Detection and Bioimaging. Mater. Chem. Front. 2019, 3, 2388-2396. [CrossRef]

15. Rowan, S.J.; Cantrill, S.J.; Stoddart, J.F. Triphenylphosphonium-Stoppered [2]Rotaxanes. Org. Lett. 1999, 1, 129-132. [CrossRef]

16. Ashton, P.R.; Baxter, I.; Fyfe, M.C.T.; Raymo, F.M.; Spencer, N.; Stoddart, J.F.; White, A.J.P.; Williams, D.J. Rotaxane or Pseudorotaxane? That Is the Question! J. Am. Chem. Soc. 1998, 120, 2297-2307. [CrossRef]

17. Sohgawa, Y.; Fujimori, H.; Shoji, J.; Furusho, Y.; Kihara, N.; Takata, T. Polyslipping: A New Approach to Polyrotaxane-like Assemblies. Chem. Lett. 2001, 30, 774-775. [CrossRef]

18. Tokunaga, Y.; Yoshioka, M.; Nakamura, T.; Goda, T.; Nakata, R.; Kakuchi, S.; Shimomura, Y. Do Dibenzo[22-30]Crown Ethers Bind Secondary Ammonium Ions to Form Pseudorotaxanes? Bull. Chem. Soc. Jpn. 2007, 80, 1377-1382. [CrossRef]

19. Leung, K.C.-F.; Lau, K.-N.; Wong, W.-Y. Revisiting the Formation and Tunable Dissociation of a [2]Pseudorotaxane Formed by Slippage Approach. Int. J. Mol. Sci. 2015, 16, 8254-8265. [CrossRef] [PubMed]

20. Leung, K.C.-F.; Lau, K.-N. Self-assembly and Thermodynamic Synthesis of Rotaxane Dendrimers and Related Structures. Polym. Chem. 2010, 1, 988-1000. [CrossRef]

21. Rowan, S.J.; Cantrill, S.J.; Cousins, G.R.L.; Sanders, J.K.M.; Stoddart, J.F. Dynamic Covalent Chemistry. Angew. Chem. Int. Ed. 2002, 41, 898-952. [CrossRef]

22. Ashton, P.R.; Fyfe, M.C.T.; Hickingbottom, S.K.; Stoddart, J.F.; White, A.J.P.; Williams, D. Hammett Correlations `Beyond the Molecule'. J. Chem. Soc. Perkin Trans. 2 1998, 10, 2117-2128. [CrossRef]

23. Ashton, P.R.; Bartsch, R.A.; Cantrill, S.J.; Hanes, R.E.; Hickingbottom, S.K.; Lowe, J.N.; Preece, J.A.; Stoddart, J.F.; Talanov, V.S.; Wang, Z.-H. Secondary Dibenzylammonium Ion Binding by [24]Crown-8 and [25]Crown-8 Macrocycles. Tetrahedron Lett. 1999, 40,3661-3664. [CrossRef]

24. Zhang, C.; Li, S.; Zhang, J.; Zhu, K.; Li, N.; Huang, F. Benzo-21-Crown-7/Secondary Dialkylammonium Salt [2]Pseudorotaxaneand [2]Rotaxane-Type Threaded Structures. Org. Lett. 2007, 9, 5553-5556. [CrossRef] [PubMed]

25. Glink, P.T.; Oliva, A.I.; Stoddart, J.F.; White, A.J.P.; Williams, D.J. Template-Directed Synthesis of a [2]Rotaxane by the Clipping under Thermodynamic Control of a Crown Ether Like Macrocycle Around a Dialkylammonium Ion. Angew. Chem. Int. Ed. 2001, 40, 1870-1875. [CrossRef]

26. Han, X.; Liu, G.; Liu, S.H.; Yin, J. Synthesis of Rotaxanes and Catenanes Using an Imine Clipping Reaction. Org. Biomol. Chem. 2016, 14, 10331-10351. [CrossRef]

27. Meyer, C.D.; Joiner, C.S.; Stoddart, J.F. Template-Directed Synthesis Employing Reversible Imine Bond Formation. Chem. Soc. Rev. 2007, 36, 1705-1723. [CrossRef]

28. Wang, W.; Chen, L.-J.; Wang, X.-Q.; Sun, B.; Li, X.; Zhang, Y.; Shi, J.; Yu, Y.; Zhang, L.; Liu, M.; et al. Organometallic Rotaxane Dendrimers with Fourth-Generation Mechanically Interlocked Branches. Proc. Natl. Acad. Sci. USA 2015, 112, 5597-5601. [CrossRef]

29. Kwan, C.-S.; Zhao, R.; VanHove, M.A.; Cai, Z.; Leung, K.C.-F. Higher-Generation Type III-B Rotaxane Dendrimers with Controlling Particle Size in Three-Dimensional Molecular Switching. Nat. Commun. 2018, 9, 497. [CrossRef]

30. Wang, X.-Q.; Wang, W.; Li, W.-J.; Chen, L.-J.; Yao, R.; Yin, G.-Q.; Wang, Y.-X.; Zhang, Y.; Huang, J.; Tan, H.; et al. Dual StimuliResponsive Rotaxane-Branched Dendrimers with Reversible Dimension Modulation. Nat. Commun. 2018, 9, 3190. [CrossRef] [PubMed]

31. Kwan, C.-S.; Wang, T.; Li, M.; Chan, A.S.C.; Cai, Z.; Leung, K.C.-F. Type III-C Rotaxane Dendrimers: Synthesis, Dual Size Modulation and in Vivo Evaluation. Chem. Commun. 2019, 55, 13426-13429. [CrossRef] [PubMed]

32. Wang, X.-Q.; Li, W.-J.; Wang, W.; Wen, J.; Zhang, Y.; Tan, H.; Yang, H.-B. Construction of Type III-C Rotaxane-Branched Dendrimers and Their Anion-Induced Dimension Modulation Feature. J. Am. Chem. Soc. 2019, 141, 13923-13930. [CrossRef]

33. Watanabe, N.; Yagi, T.; Kihara, N.; Takata, T. Highly Efficient Synthesis of [3]- and [5]-Rotaxanes Consisting of Crown Ether and a Sec-Ammonium Salt. Chem. Commun. 2002, 22, 2720-2721. [CrossRef]

34. Chwalek, M.; Auzély, R.; Fort, S. Synthesis and Biological Evaluation of Multivalent Carbohydrate Ligands Obtained by Click Assembly of Pseudo-Rotaxanes. Org. Biomol. Chem. 2009, 7, 1680-1688. [CrossRef]

35. Belowich, M.E.; Valente, C.; Stoddart, J.F. Template-Directed Syntheses of Rigid Oligorotaxanes under Thermodynamic Control. Angew. Chem. Int. Ed. 2010, 49, 7208-7212. [CrossRef] [PubMed]

36. Belowich, M.E.; Valente, C.; Smaldone, R.A.; Friedman, D.C.; Thiel, J.; Cronin, L.; Stoddart, J.F. Positive Cooperativity in the Template-Directed Synthesis of Monodisperse Macromolecules. J. Am. Chem. Soc. 2012, 134, 5243-5261. [CrossRef] [PubMed]

37. Gothard, C.M.; Bruns, C.J.; Gothard, N.A.; Grzybowski, B.A.; Stoddart, J.F. Modular Synthesis of Bipyridinium Oligomers and Corresponding Donor-Acceptor Oligorotaxanes with Crown Ethers. Org. Lett. 2012, 14, 5066-5069. [CrossRef] [PubMed]

38. Zhu, Z.; Bruns, C.J.; Li, H.; Lei, J.; Ke, C.; Liu, Z.; Shafaie, S.; Colquhoun, H.M.; Stoddart, J.F. Synthesis and Solution-State Dynamics of Donor-acceptor Oligorotaxane Foldamers. Chem. Sci. 2013, 4, 1470-1483. [CrossRef] 
39. Amabilino, D.B.; Ashton, P.R.; Bělohradský, M.; Raymo, F.M.; Stoddart, J.F. The Controlled Self-Assembly of a [3]Rotaxane Incorporating Three Constitutionally Different Components. J. Chem. Soc. Chem. Commun. 1995, 7, 747-750. [CrossRef]

40. Fuller, A.-M.L.; Leigh, D.A.; Lusby, P.J. Sequence Isomerism in [3]Rotaxanes. J. Am. Chem. Soc. 2010, 132, 4954-4959. [CrossRef]

41. Joosten, A.; Trolez, Y.; Heitz, V.; Sauvage, J.-P. Use of Cleavable Coordinating Rings as Protective Groups in the Synthesis of a Rotaxane with an Axis That Incorporates More Chelating Groups Than Threaded Macrocycles. Chem. Eur. J. 2013, 19, 12815-12823. [CrossRef]

42. Wilson, E.A.; Vermeulen, N.A.; McGonigal, P.R.; Avestro, A.J.; Sarjeant, A.A.; Stern, C.L.; Stoddart, J.F. Formation of a Hetero[3]Rotaxane by a Dynamic Component-Swapping Strategy. Chem. Commun. 2014, 50, 9665-9668. [CrossRef]

43. Neal, E.A.; Goldup, S.M. A Kinetic Self-Sorting Approach to Heterocircuit [3]Rotaxanes. Angew. Chem. Int. Ed. 2016, 55, 12488-12493. [CrossRef]

44. Lewis, J.E.M.; Winn, J.; Cera, L.; Goldup, S.M. Iterative Synthesis of Oligo[n]Rotaxanes in Excellent Yield. J. Am. Chem. Soc. 2016, 138, 16329-16336. [CrossRef] [PubMed]

45. Wang, X.-Q.; Li, W.-J.; Wang, W.; Yang, H.-B. Heterorotaxanes. Chem. Commun. 2018, 54, 13303-13318. [CrossRef] [PubMed]

46. Leung, K.C.-F.; Wong, W.Y.; Aricó, F.; Haussmann, P.C.; Stoddart, J.F. The Stability of Imine-Containing Dynamic [2]Rotaxanes to Hydrolysis. Org. Biomol. Chem. 2010, 8, 83-89. [CrossRef] [PubMed]

47. Wong, W.-Y.; Leung, K.C.-F.; Stoddart, J.F. Self-Assembly, Stability Quantification, Controlled Molecular Switching, and Sensing Properties of an Anthracene-Containing Dynamic [2]Rotaxane. Org. Biomol. Chem. 2010, 8, 2332-2343. [CrossRef] [PubMed]

48. Yoon, I.; Narita, M.; Goto, M.; Shimizu, T.; Asakawa, M. Synthesis of a [2]Rotaxane Incorporating a Ni(II)-Salen Moiety: Evidence of Ring-Opening-and-Closing Protocol. Org. Lett. 2006, 8, 2341-2344. [CrossRef]

49. Narita, M.; Yoon, I.; Aoyagi, M.; Goto, M.; Shimizu, T.; Asakawa, M. Transition Metal(II)-Salen and -Salophen Macrocyclic Complexes for Rotaxane Formation: Syntheses and Crystal Structures. Eur. J. Inorg. Chem. 2007, 2007, 4229-4237. [CrossRef]

50. Pun, A.; Hanifi, D.A.; Kiel, G.; O’Brien, E.; Liu, Y. Facile Route to an All-Organic, Triply Threaded, Interlocked Structure by Templated Dynamic Clipping. Angew. Chem. Int. Ed. 2012, 51, 13119-13122. [CrossRef]

51. Pun, A.B.; Gagnon, K.J.; Klivansky, L.M.; Teat, S.J.; Li, Z.T.; Liu, Y. Solvent-Driven Selective $\pi$-Cation Templating in Dynamic Assembly of Interlocked Molecules. Org. Chem. Front. 2014, 1, 167-175. [CrossRef]

52. Tachibana, Y.; Kawasaki, H.; Kihara, N.; Takata, T. Sequential O- and N-Acylation Protocol for High-Yield Preparation and Modification of Rotaxanes: Synthesis, Functionalization, Structure, and Intercomponent Interaction of Rotaxanes. J. Org. Chem. 2006, 71, 5093-5104. [CrossRef] [PubMed]

53. Berná, J.; Alajarín, M.; Martínez-Espín, J.S.; Buriol, L.; Martins, M.A.P.; Orenes, R.-Á. Dampened Circumrotation by CH. . $\pi$ Interactions in Hydrogen Bonded [2]Rotaxanes. Chem. Commun. 2012, 48, 5677-5679. [CrossRef]

54. Yao, J.; Fu, X.; Zheng, X.-L.; Cao, Z.-Q.; Qu, D.-H. Two Functional [2]Rotaxanes Featuring Efficient Intercomponent Interactions between Chromophores. Dyes Pigm. 2015, 121, 13-20. [CrossRef]

55. Orlando, T.; Salbego, P.R.S.; Farias, F.F.S.; Weimer, G.H.; Copetti, J.P.P.; Bonacorso, H.G.; Zanatta, N.; Hoerner, M.; Berná, J.; Martins, M.A.P. Crystallization Mechanisms Applied to Understand the Crystal Formation of Rotaxanes. Eur. J. Org. Chem. 2019, 2019, 187010. [CrossRef]

56. Salbego, P.R.S.; Orlando, T.; Farias, F.F.S.; Bonacorso, H.G.; Martins, M.A.P. [2]Rotaxanes Bearing a Tetralactam Macrocycle: The Role of a Trifurcated Hydrogen Bond in the Crystalline State. Eur. J. Org. Chem. 2019, 2019, 3464-3471. [CrossRef]

57. Martinez-Cuezva, A.; Morales, F.; Marley, G.R.; Lopez-Lopez, A.; Martinez-Costa, J.C.; Bautista, D.; Alajarin, M.; Berna, J. Thermally and Photochemically Induced Dethreading of Fumaramide-Based Kinetically Stable Pseudo[2]Rotaxanes. Eur. J. Org. Chem. 2019, 2019, 3480-3488. [CrossRef]

58. Leung, K.C.-F.; Xuan, S.; Lo, C.-M. Reversible Switching between Hydrophilic and Hydrophobic Superparamagnetic Iron Oxide Microspheres via One-Step Supramolecular Dynamic Dendronization: Exploration of Dynamic Wettability. ACS Appl. Mater. Interfaces 2009, 1, 2005-2012. [CrossRef] [PubMed] 